in vivo $34: 2049-2055(2020)$

doi:10.21873/invivo.12006

\title{
Epidemiological Analysis of Zygomatic Bone Fractures in North-Western Romanian Population: A 10-Year Retrospective Study
}

\author{
PAUL ANDREI T,ENT, RALUCA-IULIA JUNCAR and MIHAI JUNCAR \\ Department of Oral and Maxillofacial Surgery, University of Oradea, Oradea, Romania
}

\begin{abstract}
Background/Aim: Midface fractures represent a challenge for medical practitioners due to the severe esthetic and functional consequences. This study aimed to determine the causes and to provide a demographic analysis of zygomatic bone fractures in our geographical area, with a view to implementing the necessary prevention methods, training the medical staff for a certain type of patients and decreasing the required costs. Patients and Methods: A retrospective statistical epidemiological analysis of 242 patients with zygomatic bone fractures over a 10-year period was performed. Results: The most affected age group was 20-29 years (27.27\%). The most affected were men ( $n=211,87.19 \%)$ from urban areas $(n=140$, $57.85 \%)$, and without education $(n=122,50.41 \%)$. The most frequent cause was interpersonal violence (54.04\%), followed by falls (17.36\%) and road traffic accidents (16.53\%). Conclusions: Interpersonal violence as a cause of zygomatic bone fractures is currently reaching epidemic proportions. Taking legal measures to prevent aggression is a public health emergency that would considerably decrease the incidence of these fractures in our population.
\end{abstract}

Zygomatic bone fractures are a pathology that challenges surgeons worldwide, representing the most frequent type of midface fracture in our geographical area $(1,2)$. This pathology can have severe aesthetic and functional consequences, leading to marked facial asymmetry, visual disorders, associated ophthalmic lesions, limited mouth opening, as well as sensory disorders in the territory of the infraorbital nerve (3). The complexity of these fractures is

This article is freely accessible online.

Correspondence to: Juncar Raluca-Iulia, Faculty of Medicine and Pharmacy, University of Oradea, Oradea, Str. Piața 1 Decembrie, no. 10, 410073, Romania. Tel: +40 742232890, Fax: +40 259432789, e-mail: ralucajuncar@yahoo.ro

Key Words: Zygomatic, fracture, trauma, etiology, epidemiological. directly proportional to the etiology, direction and kinetic energy of the wounding agent, its acceleration speed change, and not least, to the surface of contact and the duration of the impact with the recipient $(4,5)$. The treatment of zygomatic bone fractures varies from simple conservative methods to complex surgical methods that require high medical costs (6). No allocation of necessary funds for the treatment of this type of pathophysiology can affect the postoperative outcome and favorable evolution over time, which is frequently found in developing countries (7).

The etiology of zygoma fractures is a subject of interest in the literature and is influenced by: i) the geographical region, ii) population density, iii)the level of education and iv) the environment of origin, such as the social, economic, cultural or religious status of patients $(2,7,8)$. Knowing the main type of etiology, the demographic pattern and the epidemiology of this condition is extremely important in order to take prophylactic measures and redistribute financial resources in health care $(8,9)$. Recently, such etiological studies have been conducted both in Europe and internationally, but unfortunately, few of them refer strictly to zygomatic bone fractures, despite the increased incidence and the high resource consumption of these fractures $(2,9-11)$.

The aim of this study is to determine the main traumatic etiology and the epidemiology of zygomatic bone fractures in order to develop and subsequently implement methods for their prevention, in the context of the absence of studies related to this aspect in our geographical area.

\section{Patients and Methods}

For this study, the patients admitted and treated in the Oral and Maxillofacial Surgery Clinic I in Cluj-Napoca over a period of 10 years were available. During this time period, patients admitted and treated for zygomatic bone fractures were selected retrospectively. The study was approved by the Ethics Committee of Oradea University (Nr. 1237/15.10.2018). All patients included in the study signed an informed consent at the time of admission to the clinical service, by which they gave their consent for the use of their anonymized medical data for scientific purposes. The study inclusion 


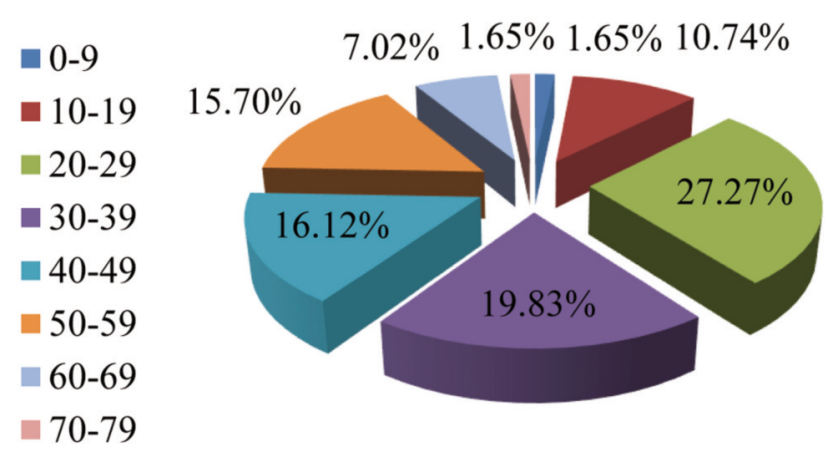

Figure 1. Distribution of patients by age.

criteria were: i) presence of at least one fracture line in the zygomatic bone or its sutures, ii) an episode of acute trauma in the disease history, iii) paraclinical examinations (radiographic or computed tomographic examination) confirming the clinical diagnosis of fracture and iv) evidencing the location and characteristics of the fracture, as well as its treatment in the study host institution.

Exclusion criteria involved: i) patient without fracture lines in the zygomatic bone or its sutures, ii) zygomatic bone fractures associated with orbital fractures, iii) pathological bone fracture, iv) absence of complementary imaging investigations, v) treatment performed in another service, vi) incomplete data, and vii) presence of factors favoring the development of fractures, such as bisphosphonate treatment, osteopathies etc.

The data were extracted from patients' medical records, and the following variables divided into subgroups were monitored: i) sex (male/female), ii) age (divided into 10-year age-groups), iii) environment of origin (urban/rural), iv) level of education (no studies: patients having completed the 1st grade of primary school; primary school: the highest education level completed; middle school: the highest education level completed; high school: the highest education level completed; university studies: patients having graduated from a faculty), and v) traumatic etiology.

This study was approved by the Territorial Ethics Commission and have therefore been performed in accordance with the ethical standards laid down in the 1964 Declaration of Helsinki and its later amendments (12).

The data were centralized in electronic format using Microsoft Excel software. Descriptive statistics analysis of the evaluated cases was performed with a two decimal percentage accuracy. Statistical processing was performed using the MedCalc Statistical Software version 17.2 (MedCalc Software bvba, Ostend, Belgium). Continuous data were expressed as mean and standard deviation, while nominal data were expressed as frequency and percentage. The frequencies of a nominal variable among the categories of another nominal variable were compared to one another using the chi-square test. The comparison of a continuous nominal variable between two groups was performed using the $t$-test for independent variables. A value of $p<0.05$ was considered statistically significant.

\section{Results}

Of all patients admitted with fractures located in the zygomatic bone over the 10-year period, 242 patients met all

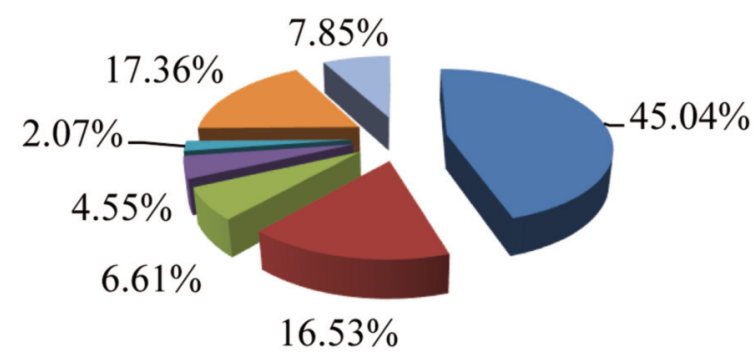

\section{- Interpersonal violence $\quad$ Road traffic accident - Domestic accident - Work accident - Sports injury accident - Fall}

Figure 2. Distribution of patients depending on traumatic etiology.

the study inclusion criteria. The most affected age group was 20-29 years, followed by 30-39 years (Figure 1). The incidence of zygomatic bone fractures was higher among men $(M)(n=211,87.19 \%)$ compared to women $(F)(n=31$, $12.81 \%)$. The $\mathrm{M} / \mathrm{F}$ ratio was $6.8: 1$. Patients living in urban areas $(n=140,57.85 \%)$ were more affected by zygomatic bone fractures than those living in rural areas $(n=102$, 42.15\%). Zygomatic bone fractures had the highest incidence among patients without education $(n=122,50.41 \%)$, while patients with various education levels were less affected: i) primary school $(n=20,8.26 \%)$, ii) middle school $(n=40$, $16.53 \%)$, iii) high school ( $\mathrm{n}=41,16.94 \%)$, and iv) higher education $(n=19,7.85 \%)$. The most frequent cause of zygomatic bone fractures in our geographical area was due to interpersonal violence (IPV), followed by falls and road traffic accidents (RTA) (Figure 2).

Statistical correlation of the etiology of zygomatic bone fractures with the sex, the environment of origin and the education level of patients was performed. Men were more predisposed to zygomatic bone fractures than women, regardless of the type of etiology $(p=0.002)$ (Table I). Patients from rural areas were more predisposed to fractures through interpersonal violence, animal attacks and domestic accidents, while in urban areas, patients were more predisposed to fractures through interpersonal violence, road traffic accidents or falls $(p=0.005)$ (Table II). Patients without education were more predisposed to zygomatic bone fractures of all etiological categories, except for road traffic accidents, where high school graduates were predominant $(p=0.000)$ (Table III). These results are statistically significant.

\section{Discussion}

Zygomatic bone fractures were found in the highest proportion in the 20-29 age group, in accordance with the 
Țent et al: Epidemiology of Zygomatic Bone Fractures

Table I. Distribution of the types of traumatic etiology depending on gender.

\begin{tabular}{lcccccccc}
\hline Gender & \multicolumn{9}{c}{ Etiology } & Total \\
\cline { 2 - 8 } & IPV & RTA & Domestic accident & Sports injury & Work accident & Fall & Animal attack \\
\hline Female & 6 & 13 & 1 & 0 & 1 & 7 & 3 & 31 \\
& $5.7 \%$ & $32.5 \%$ & $6.3 \%$ & $0.0 \%$ & $20.0 \%$ & $16.7 \%$ & $15.0 \%$ & $12.8 \%$ \\
Male & 101 & 27 & 15 & 12 & 4 & 35 & 17 & 211 \\
& $94.3 \%$ & $67.5 \%$ & $93.8 \%$ & $100.0 \%$ & $80.0 \%$ & $83.3 \%$ & $85.0 \%$ & $87.2 \%$ \\
Total & 107 & 40 & 16 & 12 & 5 & 42 & 20 & 242 \\
$p=0.002$ & $100 \%$ & $100 \%$ & $100 \%$ & $100 \%$ & $100 \%$ & $100 \%$ & $100 \%$ & $100 \%$ \\
\hline
\end{tabular}

IPV: Interpersonal violence; RTA: road traffic accident.

Table II. Distribution of the types of traumatic etiology depending on the environment.

\begin{tabular}{|c|c|c|c|c|c|c|c|c|}
\hline \multirow[t]{2}{*}{ Environment } & \multicolumn{7}{|c|}{ Etiology } & \multirow[t]{2}{*}{ Total } \\
\hline & IPV & RTA & Domestic accident & Sports injury & Work accident & Fall & Animal attack & \\
\hline \multirow[t]{2}{*}{ Rural } & 40 & 15 & 11 & 2 & 2 & 18 & 15 & 103 \\
\hline & $36.8 \%$ & $37.5 \%$ & $68.8 \%$ & $16.7 \%$ & $40.0 \%$ & $42.9 \%$ & $75.0 \%$ & $42.6 \%$ \\
\hline \multirow[t]{2}{*}{ Urban } & 67 & 25 & 5 & 10 & 3 & 24 & 5 & 139 \\
\hline & $63.2 \%$ & $62.5 \%$ & $31.3 \%$ & $83.3 \%$ & $60.0 \%$ & $57.1 \%$ & $25.0 \%$ & $57.4 \%$ \\
\hline Total & 107 & 40 & 16 & 12 & 5 & 42 & 20 & 242 \\
\hline$p=0.006$ & $100 \%$ & $100 \%$ & $100 \%$ & $100 \%$ & $100 \%$ & $100 \%$ & $100 \%$ & $100 \%$ \\
\hline
\end{tabular}

IPV: Interpersonal violence; RTA-road traffic accident.

results from other studies $(3,4,9,13-19)$. This is due to the fact that during this period of life, individuals are more socially, culturally, and physically active, making them more exposed to risks factors through their actions (13-19). Another favoring factor, which cannot be neglected and is specific to this age group, is alcohol consumption (20). Additionally, high-speed driving by young and inexperienced drivers, often predisposed to overlooking or deliberately disregarding the traffic rules, can result in higher numbers of road traffic accidents (21).

The current study indicates a low incidence of zygomatic bone fractures in the first decade of life. This result is confirmed by other studies and explained by the fact that at this age, parental supervision is greater and the anatomical particularities of children, such as bone suture elasticity and incomplete pneumatization of paranasal sinuses make the bone more malleable and allow it to better absorb traumatic shocks $(14,21-23)$.

The predominance of the male sex among patients with zygomatic bone fractures is also found in other studies $(3,9-$ $11,13,15,16-19,22,24)$. From a behavioral point of view, it is known that men are more aggressive and more conflicting than women, and as a consequence they are more predisposed to trauma (25). Professionally and socially, men are more frequently involved in physical, agricultural work or extreme sports $(21,22)$. In this context, they are more susceptible to experience maxillofacial fractures following work accidents, sports injuries or animal attacks compared to women (21-25). This is precisely why increased male:female ratios are noteworthy in regions such as Saudi Arabia [7.7:1 (11) or 8:1 (26)], where women are forbidden from participating in many social activities, as well as driving (27). In contrast, in countries, such as Norway (15) or Switzerland (9), where women are not banned from participating in social activities, the sex ratios in the case of zygomatic bone fractures decrease.

Regarding the environment of origin, our results are in accordance with those of the literature, as increased incidence of zygomatic bone fractures in urban areas are also reported by other authors (2, 3, 28-30). The elevated population density in cities, the advanced infrastructure with highways allowing high-speed circulation of vehicles, the marked discrepancies between social classes compared to a rural environment are concurrent factors that increase the risk of trauma in urban areas (28-31). Contrary to our studies, Smith H. et al. (32) have reported a higher frequency of zygomatic bone fractures in rural areas. However, the authors confirm that the unit where the study was conducted serves multiple rural regions. It should be noted that in our study there was a high incidence of interpersonal violence in 
in vivo $34: 2049-2055(2020)$

Table III. Distribution of the types of traumatic etiology depending on the level of education.

\begin{tabular}{|c|c|c|c|c|c|c|c|c|}
\hline \multirow{2}{*}{$\begin{array}{l}\text { Level of } \\
\text { education }\end{array}$} & \multicolumn{7}{|c|}{ Etiology } & \multirow[t]{2}{*}{ Total } \\
\hline & IPV & RTA & Domestic accident & Sports injury & Work accident & Fall & Animal attack & \\
\hline \multirow[t]{2}{*}{ No education } & 59 & 15 & 10 & 5 & 2 & 24 & 7 & 122 \\
\hline & $46.7 \%$ & $38.5 \%$ & $71.4 \%$ & $41.7 \%$ & $40.0 \%$ & $63.2 \%$ & $36.8 \%$ & $48.1 \%$ \\
\hline \multirow{2}{*}{ Primary school } & 8 & 1 & 0 & 0 & 0 & 2 & 9 & 20 \\
\hline & $6.7 \%$ & $2.6 \%$ & $0.0 \%$ & $0.0 \%$ & $0.0 \%$ & $5.3 \%$ & $47.4 \%$ & $8.6 \%$ \\
\hline \multirow[t]{2}{*}{ Middle school } & 19 & 5 & 3 & 3 & 1 & 7 & 2 & 40 \\
\hline & $18.1 \%$ & $12.8 \%$ & $21.4 \%$ & $25.0 \%$ & $20.0 \%$ & $18.4 \%$ & $10.5 \%$ & $17.2 \%$ \\
\hline \multirow[t]{2}{*}{ High school } & 17 & 16 & 0 & 2 & 1 & 4 & 1 & 41 \\
\hline & $17.1 \%$ & $41.0 \%$ & $0.0 \%$ & $16.7 \%$ & $20.0 \%$ & $10.5 \%$ & $5.3 \%$ & $18.0 \%$ \\
\hline \multirow{2}{*}{$\begin{array}{l}\text { University } \\
\text { studies }\end{array}$} & 12 & 2 & 1 & 2 & 1 & 1 & 0 & 19 \\
\hline & $11.4 \%$ & $5.1 \%$ & $7.1 \%$ & $16.7 \%$ & $20.0 \%$ & $2.6 \%$ & $0.0 \%$ & $8.2 \%$ \\
\hline Total & 107 & 39 & 14 & 12 & 5 & 38 & 19 & 242 \\
\hline$p=0.000$ & $100 \%$ & $100 \%$ & $100 \%$ & $100 \%$ & $100 \%$ & $100 \%$ & $100 \%$ & $100 \%$ \\
\hline
\end{tabular}

IPV: Interpersonal violence; RTA-road traffic accident.

both urban and rural areas. This is quite rarely found in the literature $(14,28)$.

The majority of zygomatic bone fractures were registered for patients without education, which has been reported by other authors as well (33-35). The lack of education or a higher qualification predisposes to unemployment, a low social status, material deficiencies, and limited access to health care services (33). All this leads to frustration, predisposing this category of patients to conflicts or interpersonal violence and implicitly, to cervicofacial trauma (36). Higher education can provide, in addition to a superior social status, health education for the prevention of diseases through an adequate diet, a balanced lifestyle and an awareness of social, cultural and legislative norms (34-37). All these contribute to a decrease in the risk of exposure to trauma (36). The literature reports extremely low incidences of zygomatic bone fractures due to interpersonal violence among patients with higher education $(34,36)$.

The great number of zygomatic bone fractures through aggression can be explained by the prominence of the zygomatic bone, which is exposed to direct blows to the face (2). Interpersonal violence as a main etiological factor has been identified in other epidemiological studies conducted in: Brazil (27), Bulgaria (2, 37), Norway (2, 14), Sweden (38), Italy (3), and USA (10). Boffano P et al. (2) have reported in their EURMAT study, in collaboration with multiple centers in Europe, that interpersonal violence is the main etiology among zygomatic bone fractures in Serbia, Ukraine, Estonia and UK (2). Hallmer F. et al. (38) have also reported that the number of interpersonal violence injuries exceeds that of road traffic injuries. Some authors maintain that the predominance of zygomatic bone fractures in developed countries can be caused by interpersonal conflicts resulting from frustration secondary to the great differences between social classes or by the wide access of the population to alcohol $(2,3,10,38)$. Many literature studies consider that there is an interrelation between alcohol consumption and aggression $(2,15,39,40)$. A proof is represented by Arab countries, where the wide limitation of access to alcoholic beverages leads to a reduced number of interpersonal violence injuries $(11,13)$. According to the EURMAT study (2), in other European countries, such as France, Netherlands and Croatia, the main etiology of zygomatic bone fractures is represented by falls. This etiology is also found in other regions, such as Switzerland (9), Brazil, the Sao Paulo area $(41,42)$, and Israel $(43)$. The incidence of zygomatic bone fractures through falls can be attributed to population aging (2-4). Another aspect that should not be overlooked is the possibility that injuries from falls may be secondary to undeclared aggression, or the possible deliberate misreporting of aggression as a fall for various personal reasons or out of fear $(2,3,10,11,13-14,25-31)$.

In contrast, zygomatic bone fractures due to road traffic accidents are predominant in other regions: Saudi Arabia (11, 12), Malaysia (23), South Korea (16), India (17), China (4), Iran (19), Nigeria (44), Uganda (45). Road traffic accidents are predominant in developing countries where there are no well-defined traffic rules, such as the obligation of wearing a seatbelt, special equipment for motorcycles or a helmet for bicycles $(11,13-17,44-47)$. However, road traffic accidents are also predominant in developed countries with a high population density and a great number of vehicles, leading to a statistically higher risk of road traffic accidents $(4,16$, $17,44,45)$. The well-defined traffic rules in Romania are responsible for the limited zygomatic bone fractures caused by road traffic accidents. One thing to mention concerning our results is the fact that here we excluded patients with associated orbital wall fractures, as it is known that the high kinetic energy in the case of road traffic accidents 
predisposes to complex zygomatico-orbital or panfacial fractures $(4,16,17,44,45)$. The exclusion of these patients from the study explains the low rate of road traffic accidents. Zygomatic bone fractures from animal attacks or domestic accidents were found in low numbers in our study and were representative of the rural environment. This is also in line with the literature $(14,28)$.

Demographic and epidemiological analyses are extremely important in a given territory, providing vital indicators for the organization of financial resources pertaining to a particular type of trauma, the estimation of expenses for collaboration with national health insurances, the training of ambulatory care staff to collaborate with a certain type of patients and, most importantly, the implementation of norms for the prevention of the pathology concerned. We consider this study to be extremely important in the context of the absence of data in Western Romania regarding the epidemiology of zygomatic bone fractures and maxillofacial injuries in general. In this context, the data obtained are representative and have a scientific and clinical impact.

Nevertheless, the current study has a series of limitations. The most important limitation results from the retrospective nature of the research, the data collected from medical records depending on the accuracy with which they were registered and under the standard that they were presented at the time. Another limitation is derived from patients' ability or wish to report incorrect data in order to avoid legal consequences.

In conclusion, the main cause of zygomatic bone fractures in Western Romania is interpersonal violence. The distribution area of interpersonal violence is large, reaching epidemic proportions in both urban and rural environments. The major risk category is represented by men without education, during the third decade of their life. Implementing laws to increase the criminal liability of the aggressor, as well as educating the population would rapidly decrease the number of zygomatic bone fractures in Romania.

\section{Conflicts of Interest}

The Authors declare no conflicts of interest.

\section{Authors' Contributions}

Conceptualization, research, methodology and writing of the original draft was done by ȚPA; Formal analysis and data curation was done by RIJ; JM validated the data, reviewed and edited the manuscript and supervised the study.

\section{References}

1 Tent P A, Juncar R I, Lung T and Juncar M: Midfacial fractures: A retrospective etiological study over a 10 -year period in
Western Romanian population. Niger J Clin Pract 21: 15701575, 2018. PMID: 30560819. DOI: 10.4103/njcp.njcp_256_18

2 Boffano P, Roccia F, Zavattero E, Dediol E, Uglešić V, Kovačič Ž, Vesnaver A, Konstantinović VS, Petrović M, Stephens J, Kanzaria A, Bhatti N, Holmes S, Pechalova PF, Bakardjiev AG, Malanchuk VA, Kopchak AV, Galteland P, Mjøen E, Skjelbred P, Bertin H, Marion F, Guiol J, Corre P, Løes S, Lekven N, Laverick S, Gordon P, Tamme T, Akermann S, Karagozoglu KH, Kommers SC and Forouzanfar T : Assault-related maxillofacial injuries: the results from the European Maxillofacial Trauma (EURMAT) multicenter and prospective collaboration. Oral Surg Oral Med Oral Pathol Oral Radiol 119(4): 385-391, 2019. PMID: 25640305. DOI: 10.1016/j.oooo.2014.12.004

3 Brucoli M, Boffano P, Broccardo E, Benech A, Corre P, Bertin H, Pechalova P, Pavlov N, Petrov P, Tamme T, Kopchak A, Hresko A, Shuminsky E, Dediol E, Tarle M, Konstantinovic VS, Petrovic M, Holmes S, Karagozoglu KH and Forouzanfar T: The "European zygomatic fracture" research project: The epidemiological results from a multicenter European collaboration. J Craniomaxillofac Surg 47(4): 616-621, 2019. PMID: 30765246. DOI: 10.1016/j.jcms.2019.01.026

4 Mijiti A, Ling W, Tuerdi M and Maimaiti A, Tuerxun J, Tao YZ, Saimaiti A and Moming A: Epidemiological analysis of maxillofacial fractures treated at a university hospital, Xinjiang, China: A 5-year retrospective study. J Craniomaxillofac Surg 42(3): 227-233, 2014. PMID: 23791439. DOI: 10.1016/j.jcms. 2013.05.005

5 Naveen Shankar A, Naveen Shankar V, Hegde N, Sharma and Prasad R: The pattern of the maxillofacial fractures - A multicentre retrospective study. J Craniomaxillofac Surg 40(8): 675-679, 2012. PMID: 22212823. DOI: 10.1016/j.jcms.2011.11.004

6 Lee K: Global trends in maxillofacial fractures. Craniomaxillofac Trauma Reconstr 5: 213-222, 2012. PMID: 24294404. DOI: $10.1055 / \mathrm{s}-0032-132253$

7 Shayyab M, Alsoleihat F, Ryalat S and Khraisat A: Trends in the pattern of facial fractures in different countries of the world. Int J Morphol 30(2): 745-756, 2012.

8 Kostakis G, Stathopoulos P, Dais P, Gkinis G, Igoumenakis D, Mezitis M and Rallis G : An epidemiologic analysis of 1,142 maxillofacial fractures and concomitant injuries. Oral Surg Oral Med Oral Pathol Oral Radiol 1145 Suppl: S69-73, 2012. PMID: 23083959. DOI: 10.1016/j.tripleo.2011.08.029

9 Blumer M, Kumalic S, Gander T, Lanzer M, Rostetter C, Rücker $M$ and Lübbers HT: Retrospective analysis of 471 surgically treated zygomaticomaxillary complex fractures. J Craniomaxillofac Surg 46(2): 269-273, 2018. PMID: 29233697. DOI: $10.1016 / \mathrm{j} . j \mathrm{cms} .2017 .11 .010$

10 Buchanan EP, Hopper RA, Suver DW, Hayes AG, Gruss JS and Birgfeld CB: Zygomaticomaxillary complex fractures and their association with naso-orbito-ethmoid fractures: a 5-year review. Plast Reconstr Surg 130(6): 1296-1304, 2012. PMID: 23190812. DOI: $10.1097 / P R S .0 b 013 \mathrm{e} 31826 \mathrm{~d} 1643$

11 Ali-Alsuliman D, Ibrahim EH and Braimah RO: Patterns of zygomatic complex bone fracture in Saudi Arabia. J Emerg Trauma Shock 11(3): 170-174, 2018. PMID: 30429623. DOI: 10.4103/JETS.JETS_12_18

12 World Medical Association: World Medical Association Declaration of Helsinki. Ethical principles for medical research involving human subjects. Bull World Health Organ 79(4): 373374, 2001. PMID: 11357217. 
13 Abdullah WA, Al-Mutairi K, Al-Ali Y, Al-Soghier A and AlShnwani A: Patterns and etiology of maxillofacial fractures in Riyadh City, Saudi Arabia. Saudi Dent J 25(1): 33-38, 2012. PMID: 23960553. DOI: 10.1016/j.sdentj.2012.10.004

14 Batista AM, Ferreira Fde O, Marques LS, Ramos-Jorge ML and Ferreira MC: Risk factors associated with facial fractures. Braz Oral Res 26(2): 119-125, 2012. PMID: 22473346. DOI: 10.1590/s1806-83242012000200006

15 Helgeland E, Dahle IM, Leira JI and Loro LL: Maxillofacial Fractures Surgically Managed at Aalesund Hospital between 2002 and 2009. Craniomaxillofac Trauma Reconstr 8(4): 321325, 2015. PMID: 26576237. DOI: 10.1055/s-0035-1550062

16 Jin KS, Lee H, Sohn JB, Han YS, Jung DU, Sim HY and Kim HS: Fracture patterns and causes in the craniofacial region: an 8-year review of 2076 patients. Maxillofac Plast Reconstr Surg 40(1): 29, 2018. PMID: 30370262. DOI: 10.1186/s40902-018-0168-y

17 Kaul RP, Sagar S, Singhal M, Kumar A, Jaipuria J and Misra M: Burden of maxillofacial trauma at level 1 trauma center. Craniomaxillofac Trauma Reconstr 7(2): 126-130, 2014. PMID: 25071877. DOI: $10.1055 / \mathrm{s}-0034-1371539$

18 Salentijn EG, Boffano P, Boverhoff J, van den Bergh B and Forouzanfar T: The epidemiological characteristics of zygomatic complex fractures: A comparison between the surgically and non-surgically treated patients. Natl J Maxillofac Surg 4(2): 214218, 2013. PMID: 24665179. DOI: 10.4103/0975-5950.127654

19 Motamedi MH, Dadgar E, Ebrahimi A, Shirani G, Haghighat A and Jamalpour MR: Pattern of maxillofacial fractures: a 5-year analysis of 8,818 patients. J Trauma Acute Care Surg 77(4): 630-634, 2014. PMID: 25250606. DOI: 10.1097/TA. 0000000000000369

20 Lee CW, Foo QC, Wong LV and Leung YY: An overview of maxillofacial trauma in Oral and Maxillofacial Tertiary Trauma Centre, Queen Elizabeth Hospital, Kota Kinabalu, Sabah. Craniomaxillofac Trauma Reconstr 10(1): 16-21, 2017. DOI: 10.1055/s-0036-1584893

21 Qing-Bin Z, Zhao-Qiang Z, Dan C and Yan Z: Epidemiology of maxillofacial injury in children under 15 years of age in southern China. Oral Surg Oral Med Oral Pathol Oral Radiol 115(4): 43641, 2013. PMID: 22940023. DOI: 10.1016/j.oooo.2012.04.026

22 Zerfowski $\mathrm{M}$ and Bremerich A: Facial trauma in children and adolescents. Clin Oral Investig 2(3): 120-124, 1998. PMID: 9927912. DOI: $10.1007 / \mathrm{s} 007840050056$

23 Abosadegh MM, Rahman SA and Saddki N: Association of traumatic head injuries and maxillofacial fractures: A retrospective study. Dent Traumatol 33(5): 369-374, 2017. PMID: 28504848. DOI: 10.1111/edt.12349

24 Raschke GF, Rieger UM, Bader RD, Schaefer O, Guentsch A, Hagemeister $\mathrm{C}$ and Schultze-Mosgau S: The zygomaticomaxillary complex fracture - an anthropometric appraisal of surgical outcomes. J Craniomaxillofac Surg 41(4): 331-337, 2013. PMID: 23218980. DOI: 10.1016/j.jcms.2012.10.016

25 Kamath RA, Bharani S, Hammannavar R, Ingle SP and Shah AG: Maxillofacial trauma in central Karnataka, India: an outcome of 95 cases in a regional trauma care centre. Craniomaxillofac Trauma Reconstr 5(4): 197-204, 2012. PMID: 24294402. DOI: $10.1055 / \mathrm{s}-0032-1322536$

26 Al-Bokhamseen M, Salma R and Al-Bodbaij M: Patterns of maxillofacial fractures in Hofuf, Saudi Arabia: A 10-year retrospective case series. Saudi Dent J 31(1): 129-136, 2019. PMID: 30705576. DOI: 10.1016/j.sdentj.2018.10.001
27 Farias IPSE, Bernardino ÍM, Nóbrega LMD, Grempel RG and D'Avila S: Maxillofacial trauma, etiology and profile of patients: an exploratory study. Acta Ortop Bras 25(6): 258-261, 2017. PMID: 29375255. DOI: 10.1590/1413-785220172506152670

28 Batista AM, Marques LS, Batista AE, Falci SG and Ramos-Jorge ML: Urban-rural differences in oral and maxillofacial trauma. Braz Oral Res 26(2): 132-138, 2012. PMID: 22473348. DOI: 10.1590/s1806-83242012000200008

29 Hoppe IC, Kordahi AM, Paik AM, Lee ES and Granick MS: Examination of life-threatening injuries in 431 pediatric facial fractures at a level 1 trauma center. J Craniofac Surg 25(5): 1825-1828, 2014. PMID: 25203578. DOI: 10.1097/SCS. 0000000000001055

30 Manodh P, Prabhu Shankar D, Pradeep D, Santhosh R and Murugan A: Incidence and patterns of maxillofacial trauma-a retrospective analysis of 3611 patients-an update. Oral Maxillofac Surg 20(4): 377-383, 2016. PMID: 27663240. DOI: $10.1007 / \mathrm{s} 10006-016-0576-\mathrm{z}$

31 Kraft A, Abermann E, Stigler R, Zsifkovits C, Pedross F, Kloss F amd Gassner R: Craniomaxillofacial trauma: synopsis of 14,654 cases with 35,129 injuries in 15 years. Craniomaxillofac Trauma Reconstr 5(1): 41-50, 2012. PMID: 23449961. DOI: 10.1055/s-0031-1293520

32 Smith H, Peek-Asa C, Nesheim D, Nish A, Normandin P and Sahr S: Etiology, diagnosis, and characteristics of facial fracture at a midwestern level I trauma center. J Trauma Nurs 19(1): 5765, 2012. PMID: 22415509. DOI: 10.1097/JTN $0 \mathrm{~b} 013 \mathrm{e} 31823 \mathrm{a} 4 \mathrm{c} 0 \mathrm{e}$

33 Esses DF, Costa FW, Sá CD, Silva PG, Bezerra TM, Carvalho FS, de Medeiros JR and Soares EC : Occupational group, educational level, marital status and deleterious habits among individuals with maxillofacial fractures: retrospective study. Med Oral Patol Oral Cir Bucal 23(1): 13-22, 2018. PMID: 29274150. DOI: $10.4317 /$ medoral.21969

34 Oikarinen K, Schutz P, Thalib L, Sándor GK, Clokie C, Meisami T, Safar S, Moilanen M and Belal M: Differences in the etiology of mandibular fractures in Kuwait, Canada, and Finland. Dent Traumatol 20(5): 241-245, 2004. PMID: 15355381. DOI: $10.1111 / j .1600-9657.2004 .00243 . x$

35 Kar IB and Mahavoi BR: Retrospective analysis of 503 maxillofacial trauma cases in Odisha during the period of dec'04-nov'09. J Maxillofac Oral Surg 11(2): 177-181, 2012. PMID: 23730065. DOI: $10.1007 / \mathrm{s} 12663-011-0276-\mathrm{Z}$

36 Zix JA, Schaller B, Lieger O, Saulacic N, Thorén H and Iizuka $\mathrm{T}$ : Incidence, aetiology and pattern of mandibular fractures in central Switzerland. Swiss Med Wkly 141: w1320, 2011. PMID: 21618147. DOI: $10.4414 /$ smw.2011.13207

37 Bakardjiev A and Pechalova P: Maxillofacial fractures in Southern Bulgaria - a retrospective study of 1706 cases. J Cranio-Maxillo-Facial Surg 35: 147-150, 2007. PMID: 17583526. DOI 10.1016/j.jcms.2007.01.005

38 Hallmer F, Anderud J, Sunzel B, Güner N and Andersson G: Jaw fractures diagnosed and treated at Malmö University Hospital: a comparison of three decades. Int J Oral Maxillofac Surg 39(5): 446-451, 2010. PMID: 20189354. DOI: 10.1016/j.ijom. 2010.01.017

39 Watt K, Purdie DM, Roche AM and McClure RJ: Risk of injury from acute alcohol consumption and the influence of confounders. Addiction 99(10): 1262-1273, 2004. PMID: 15369564. DOI: 10.1111/j.1360-0443.2004.00823.x 
40 Chrcanovic BR: Factors influencing the incidence of maxillofacial fractures. Oral Maxillofac Surg 16(1): 3-17, 2012. PMID: 21656125. DOI: 10.1007/s10006-011-0280-y

41 Trivellato PF, Arnez MF, Sverzut CE and Trivellato AE : A retrospective study of zygomatico-orbital complex and/or zygomatic arch fractures over a 71-month period. Dent Traumatol 27: 135-142, 2011. PMID: 21385315. DOI: 10.1111/j.1600-9657.2010.00971.x

42 Gomes PP, Passeri LA and Barbosa JR: A 5-year retrospective study of zygomatico-orbital complex and zygomatic arch fractures in Sao Paulo state, Brazil. J Oral Maxillofac Surg 64: 63-67, 2006. PMID: 16360858. DOI: 10.1016/j.joms. 2005.09.012

43 Emodi O, Wolff A, Srouji H, Bahouth H, Noy D, Abu El Naaj I and Rachmiel A: Trend and demographic characteristics of maxillofacial fractures in level I trauma center. J Craniofac Surg 29: 471-475, 2018. PMID: 29194270. DOI: 10.1097/SCS. 0000000000004128

44 Ajike SO, Adebayo ET, Amanyiewe EU and Ononiwn CN: An epidemiologic survey of maxillofacial fractures and concomitant injuries in Kaduna, Nigeria. J Surg Res 27(3-4): 251-255, 2005. DOI: $10.4314 /$ njsr.v7i3.12290
45 Kamulegeya A, Lakor F and Kabenge K: Oral maxillofacial fractures seen at a Ugandan tertiary hospital: a six-month prospective study. Clinics (Sao Paulo) 64(9): 843-848, 2009. PMID: 19759877. DOI: 10.1590/S1807-59322009000900004

46 Ungari C, Filiaci F, Riccardi E, Rinna C and Iannetti G: Etiology and incidence of zygomatic fracture: a retrospective study related to a series of 642 patients. Eur Rev Med Pharmacol Sci 16(11): 1559-1562, 2012. PMID: 23111970.

47 Shapiro A, Johnson R, Miller S and McCarthy M: Facial fractures in a level I trauma centre: the importance of protective devices and alcohol abuse. Injury 32: 353-356, 2011. PMID: 11382418. DOI: 10.1016/s0020-1383(00)00245-x

Received April 5, 2020

Revised April 20, 2020

Accepted April 27, 2020 